\title{
Relationship between Sunny Crown Volume Increment and Stem Cross-Sectional Area Increment at Sunny Crown Base for Hinoki Cypress, and its Application
}

\author{
Yoshiaki Waguchi $^{* 1}$ and Masafumi Ueda ${ }^{* 2}$
}

\begin{abstract}
Vertical distribution of stem cross-sectional area increment (CSAI) for hinoki cypress can be described by combination of two linear equations derived from three tree attributes: sunny crown length (SCL), stem volume increment (SVI), and CSAI at the base of sunny crown ( $\mathrm{CSAI}_{\mathrm{SCB}}$ ). In this study, to propose a method for estimating $\mathrm{CSAI}_{\mathrm{SCB}}$, a relationship between $\mathrm{CSAI}_{\mathrm{SCB}}$ and sunny crown volume increment (SCVI) was investigated. Data were obtained from 112 sample trees selected in six stands of even-aged hinoki cypress. The proportional relation can be assumed between SCVI and $\mathrm{CSAI}_{\mathrm{SCB}}$, and the relationship could be expressed by the regression equation: $\mathrm{CSAI}_{\mathrm{SCB}}=$ $2.88 \times 10^{-4} \mathrm{SCVI}$. For each sampled tree, two vertical distributions of CSAI were obtained: one is the distribution obtained by using $\mathrm{CSAI}_{\mathrm{SCB}}$ estimated from the regression equation, and both of SCL and SVI observations, and the other is the distribution obtained by using observations of SCL, SVI, and CSAI scr. The two distributions were compared using root mean squared error (RMSE). Although the vertical distribution obtained by using $\mathrm{CSAI}_{\mathrm{SCB}}$ estimate produced a larger RMSE value than that by using CSAI $_{\mathbf{s c}}$ observation did, the difference in RMSE was small. In conclusion, the assumption of the proportional relationship between SCVI and $\mathrm{CSAI}_{\mathrm{SCB}}$ provides a useful approach for predicting vertical distribution of CSAI for hinoki cypress.
\end{abstract}

Keywords: sunny crown volume increment, stem cross-sectional area increment at sunny crown base, proportional relation, hinoki cypress

\section{INTRODUCTION}

The prediction of a tree stem form, described by the decrease in stem diameter from the butt to the apex, resulting from stand density management is important in forestry because of the economic value of timber quality. The stem diameter at a particular height depends on the previous-year stem diameter and the current-year stem cross-sectional area increment (CSAI). Therefore, the ability to predict the vertical distribution of CSAI along the stem allows the prediction of the stem form, which in turn is useful to determine the optimal

Corresponding author: Yoshiaki Waguchi

${ }^{*}$ Nara Forest Research Institute, Takatori, Nara 635-0133, Japan

${ }^{* 2}$ Laboratory of Forest Ecology, Graduate School of Agriculture, Kyoto Prefectural University, Sakyoku, Kyoto 606-8522, Japan thinning regime for a stand.

When the total height of a hinoki cypress (Chamaecyparis obtusa ENDL.) tree is known, the vertical distribution of CSAI can be described by combination of two linear equations derived from three tree attributes: sunny crown length (SCL), stem volume increment (SVI), and CSAI at the sunny crown base $\left(\mathrm{CSAI}_{\mathrm{SCB}}\right)$ (WAGUCHI and UEDA, 2006a). Since SVI often exhibit strong correlations with sunny crown dimensions such as sunny crown volume and surface area (INOSE, 1982; KAJIHARA, 1982; SAIGUSA et al., 1996), SVI would be a factor which can be estimated from sunny crown dimensions. Therefore, estimating $\mathrm{CSAI}_{\mathrm{sCB}}$ from sunny crown dimensions would make predicting the vertical distribution of CSAI from characteristics related to the sunny crown because SCL is undoubtedly a dimension of the sunny crown. However, relationships between sunny crown dimensions and $\mathrm{CSAI}_{\mathbf{s c B}}$ remain largely unexplored.

Since stem cross-sectional area at sunny crown base $\left(\mathrm{CSA}_{\mathrm{scB}}\right)$ for a tree supports mechanically the sunny crown, it is probable that the unit $\mathrm{CSA}_{\mathrm{SCB}}$ supports a constant amount of 
sunny crown. This assumption still allows the interpretation that the $\mathrm{CSAI}_{\text {scв }}$ is the result of an amount of tissue necessary to support the increments of sunny crown dimensions. If it is true, proportional relationships might exist between $\mathrm{CSA}_{\mathrm{scB}}$ and sunny crown dimensions, and between $\mathrm{CSAI}_{\mathrm{scB}}$ and increments of sunny crown dimensions. For Douglas-fir (Pseudotsuga menziesii Franco), Maguire and Hann (1989) have regressed stem sapwood cross-sectional area at crown base $\left(\mathrm{SCSA}_{\mathrm{CB}}\right)$ on the product of crown length $(\mathrm{CL})$ and square of crown radius $(\mathrm{CR})$, and on the square of stem diameter at crown base $\left(\mathrm{SD}_{\mathrm{CB}}\right)$, resulting in

$$
\mathrm{SCSA}_{\mathrm{CB}}=1.71727 \mathrm{CL} \cdot \mathrm{CR}^{2} \quad\left(R^{2}=0.701\right)
$$

and

$$
\mathrm{SCSA}_{\mathrm{CB}}=1.417224 \mathrm{SD}_{\mathrm{CB}}^{2} \quad\left(R^{2}=0.917\right)
$$

where $R^{2}$ is the coefficient of determination of the regression equation. Combining eqs. (1) and (2) gives the directly proportional relation between $\mathrm{CL} \cdot \mathrm{CR}^{2}$ and $\mathrm{SD}_{\mathrm{CB}}{ }^{2}$ (i.e., crown volume and stem cross-sectional area at crown base). This leads to the proportional relation between increments of the crown volume and the stem cross-sectional area at the crown base, and is thus expected that the sunny crown volume (SCV) and the sunny crown volume increment (SCVI) are directly proportional to the $\mathrm{CSA}_{\mathrm{ScB}}$ and the $\mathrm{CSAI}_{\mathrm{scB}}$, respectively.

The objective of this study was to propose a method for estimating $\mathrm{CSAI}_{\mathrm{SCB}}$, which could be utilized for the CSAI distribution predicting model proposed by WAGUCHI and UEDA (2006a). First, it was ascertained whether proportional relations could be assumed between $\mathrm{SCV}$ and $\mathrm{CSA}_{\mathrm{SCB}}$, and between SCVI and $\mathrm{CSAI}_{\mathrm{SCB}}$ for hinoki cypress. Next, it was confirmed that the proportional relationship between SCVI and $\mathrm{CSAI}_{\text {scB }}$ could be utilized for predicting the vertical distribution of CSAI.

\section{MATERIALS AND METHODS}

\section{Field Measurements}

Samples were obtained from six stands of even-aged hinoki cypress in Nara Prefecture, Japan. Summaries for the stands are presented in Table 1 . Stand age ranged from 10 to

Table 1 Stand descriptions

\begin{tabular}{ccccrc}
\hline Stand & $\begin{array}{c}\text { Age } \\
\text { (year) }\end{array}$ & $\begin{array}{c}\text { Density } \\
\text { (trees/ha) }\end{array}$ & $\begin{array}{c}\text { Mean diameter } \\
\text { at breast height } \\
\text { (cm) }\end{array}$ & $\begin{array}{c}\text { Mean total } \\
\text { height } \\
(\mathrm{m})\end{array}$ & $\begin{array}{c}\text { Number of } \\
\text { sample trees }\end{array}$ \\
\hline A & 10 & 5,250 & 6.8 & 5.5 & 20 \\
B & 16 & 3,006 & 11.8 & 10.1 & 15 \\
C & 19 & 3,828 & 11.9 & 9.4 & 20 \\
D & 29 & 2,602 & 12.6 & 12.7 & 22 \\
E & 41 & 1,820 & 18.6 & 16.4 & 15 \\
F & 72 & 1,000 & 29.1 & 16.8 & 20 \\
\hline
\end{tabular}

72 years, with densities ranging from 5,250 to 1,000 trees/ha, mean diameter at breast height measuring 6.8 to $29.1 \mathrm{~cm}$, and mean total height varying from 5.5 to $16.8 \mathrm{~m}$.

One hundred and twelve sample trees were selected at random in the stands. Before felling, diameter at breast height (DBH) for each tree was measured with calipers. The trees ranged from 3.6 to $32.5 \mathrm{~cm}$ in $\mathrm{DBH}$. The height of the sunny crown base for each tree was measured with a Spiegel relascope using the percentage scale. A 5 -m pole was placed upright against the tree trunk for the measurements. The SCL was calculated by subtracting the height of the sunny crown base from the total height.

After each tree was felled, the total height $(\mathrm{H})$ was measured with surveyor's tapes. The total heights ranged from 4.1 to $18.7 \mathrm{~m}$. To measure SVI and CSAI, disks were removed from the stem at stump height $(0.2 \mathrm{~m})$, at intervals of $0.5,1$, or $2 \mathrm{~m}$ below the lowest live branch, and at intervals of 0.5 or $1 \mathrm{~m}$ within the crown beginning at stump height. To measure the shape and size of the sunny crown, each segmented crown was set vertically on the ground and the crown radii at the middle of the layer were measured in four directions at right angles using surveyor's tapes.

\section{Laboratory Measurements}

The removed disks were brought to the laboratory and the annual rings were counted. For each disk, the current- and previous-year radii in four directions at right angles were measured. The current- and previous-year stem cross-sectional areas (CSAs) were calculated using average radius measurements with the stem cross section assumed to be circle in shape. The CSAI was calculated by subtracting previous-year CSA from current-year CSA. The current- and previous-year $\log$ volumes for each segment were calculated using SMALIAN's formula. The each log volume increment was calculated as the difference between the current- and previousyear log volumes. The SVI for each tree was computed as the sum of the $\log$ volume increments. The $\mathrm{CSA}_{\mathrm{SCB}}$ and $\mathrm{CSAI}_{\mathrm{SCB}}$ were estimated by interpolating from each of CSAs and CSAIs at the top and bottom of the log where the sunny crown base was located, respectively.

\section{Computation of SCV and SCVI}

To obtain SCV, the sunny crown profile for each tree was represented using the following equation:

$$
r=a_{1} z^{a_{2}}
$$

where $r$ is the crown radius (m) at the distance $z(\mathrm{~m})$ from the apex, and $a_{1}$ and $a_{2}$ are parameters. The parameters were estimated using non-linear least squares method minimizing the sum of squared residual (SSR):

$$
\mathrm{SSR}=\sum_{i=1}^{n} \sum_{j=1}^{4}\left(r_{i j}-a_{1} z_{i}^{a_{2}}\right)^{2}
$$


where $r_{i j}$ is the $j$-th crown radius $(j=1,2,3,4)$ at the $i$-th distance $z_{i}(i=1,2, \cdots, n)$ from the apex. The SCV was calculated by rotating eq. (3) on the trunk axis.

The SCVI was calculated by subtracting the previous-year SCV above the current-year sunny crown base from the current-year SCV as shown in Fig. 1. Since it is difficult to measure the previous-year SCV objectively, under the assumption that the shape and size of the previous-year sunny crown are the same as those of the current-year sunny crown, the SCVI was calculated as follows:

$$
\mathrm{SCVI}=\pi \int_{0}^{\mathrm{SCL}} r^{2} d z-\pi \int_{0}^{\mathrm{SCL}-\mathrm{HI}} r^{2} d z
$$

where $\mathrm{HI}$ is the total height increment (m/year). The assumption would be acceptable because one year is sufficiently short for the growth of the crown. The HI was calculated by subtracting the previous-year $\mathrm{H}$ from the currentyear $\mathrm{H}$. The previous-year $\mathrm{H}$ was estimated using the ordinary stem analysis technique.

Evaluation

To ascertain whether proportional relations can be assumed between $\operatorname{SCV}\left(\mathrm{m}^{3}\right)$ and $\mathrm{CSA}_{\mathrm{scB}}\left(\mathrm{m}^{2}\right)$, and between SCVI $\left(\mathrm{m}^{3} /\right.$ year) and $\mathrm{CSAI}_{\mathrm{scB}}\left(\mathrm{m}^{2} /\right.$ year $)$, the following equations were fitted using the least squares method:

$$
\mathrm{CSA}_{\mathrm{SCB}}=b_{1} \mathrm{SCV}
$$

and

$$
\mathrm{CSAI}_{\mathrm{SCB}}=b_{2} \mathrm{SCVI}
$$

where $b_{1}$ and $b_{2}$ are regression constants, and the coefficient of determination $\left(R^{2}\right)$ for each regression equation was calculated and tested statistically using the $F$-test.

WAGUCHI and UEDA (2006a) have proposed a model that predicts the vertical distribution of CSAI using the combination of two linear equations derived from SCL (m),

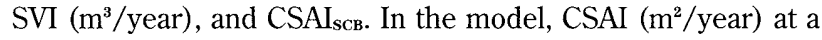
distance $z$ from the apex is expressed as

$$
\mathrm{CSAI}_{z}=c_{1} z I_{1}+\left(c_{2}+c_{3} z\right) I_{2}
$$

where $c_{1}, c_{2}$, and $c_{3}$ are parameters defined as

$$
\begin{aligned}
& c_{1}=\frac{\mathrm{CSAI}_{\mathrm{SCB}}}{\mathrm{SCL}}, \\
& c_{2}=\left(c_{1}-c_{3}\right) \mathrm{SCL}, \\
& c_{3}=\frac{2 \mathrm{SVI}-(2 \mathrm{H}-\mathrm{SCL}) \mathrm{CSAI}}{(\mathrm{H}-\mathrm{SCL})^{2}},
\end{aligned}
$$

and $I_{1}$ and $I_{2}$ are dummy variables defined as

$$
\begin{aligned}
& I_{1}=\left\{\begin{array}{ll}
1 & \text { If } 0 \leq z \leq \mathrm{SCL}, \\
0 & \text { Otherwise }
\end{array},\right. \\
& I_{2}=\left\{\begin{array}{ll}
1 & \text { If } 0 \mathrm{SCL}<z \leq \mathrm{H} \\
0 & \text { Otherwise }
\end{array},\right.
\end{aligned}
$$

Therefore, to confirm that eq. (7) representing the proportional relationship between SCVI and $\mathrm{CSAI}_{\mathrm{SCB}}$ could be utilized for the model, the root mean square error (RMSE) of eq. (8) with $\mathrm{CSAI}_{\mathrm{SCB}}$ estimated using eq. (7) was compared with that of eq. (8) with $\mathrm{CSAI}_{\mathbf{s c B}}$ observed. Both of SCL and SVI observations were substituted in eq. (8).

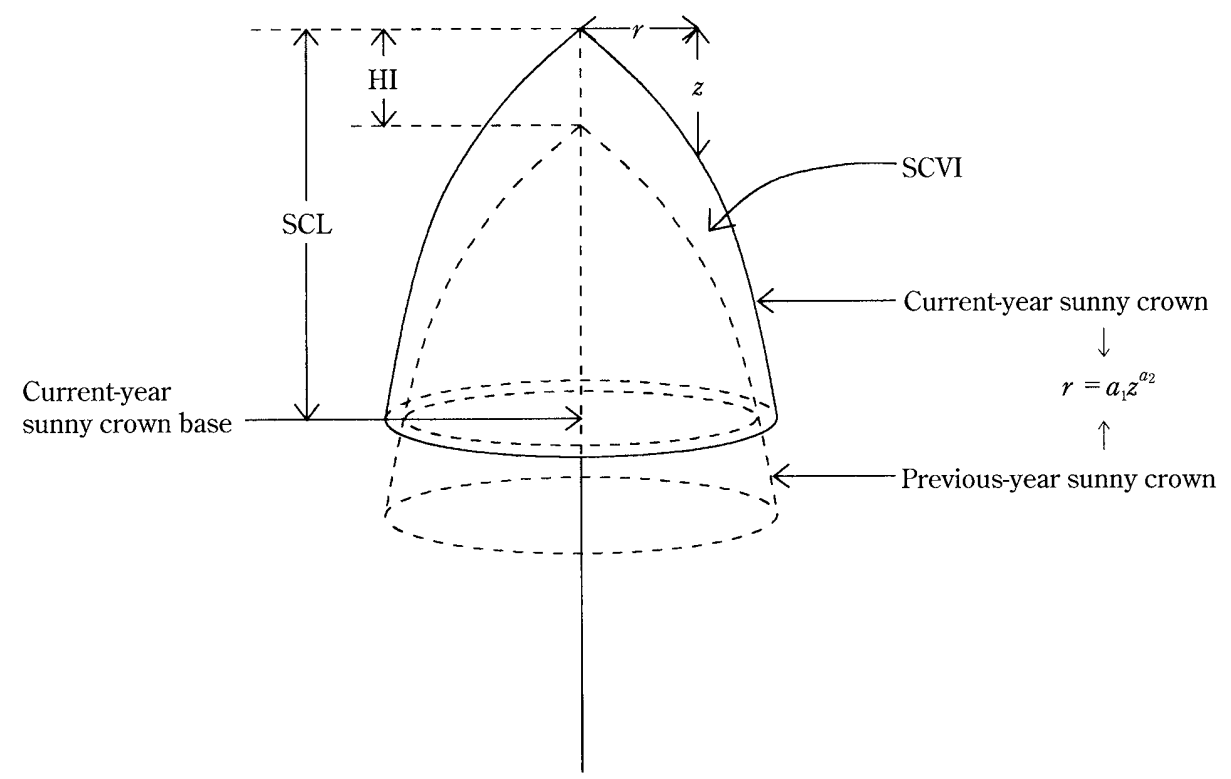

Fig. 1 Diagram of current- and previous-year sunny crowns

HI, SCL, and SCVI are the total height increment, the sunny crown length, and the sunny crown volume increment of the current year, respectively. 


\section{RESULTS AND DISCUSSION}

Fig. 2 shows the relationship between SCV and CSA $\mathrm{CcB}_{\text {scr. }}$. The $\mathrm{CSA}_{\mathrm{scB}}$ significantly increased in proportion to $\mathrm{SCV}$, and the relationship could be expressed by the following equation:

$$
\mathrm{CSA}_{\mathrm{SCB}}=3.24 \times 10^{-4} \mathrm{SCV} \quad\left(R^{2}=0.916, P<0.001\right) .
$$

Although no report has shown the proportional relation between $\mathrm{SCV}$ and $\mathrm{CSA}_{\mathrm{scB}}$ for any tree species, as mentioned above, the results for Douglas-fir by MAGUiRE and HANN (1989) describe the proportional relation between crown volume and stem cross-sectional area at crown base. The result in this study shows distinctly that the proportional relation can be assumed between SCV and $\mathrm{CSA}_{\mathrm{sc}}$ for hinoki cypress. Therefore, these results might allow the assumption that unit $\mathrm{CSA}_{\text {scв }}$ supports a constant amount of SCV, and imply the proportional relationship between SCVI and $\mathrm{CSAI}_{\text {sсв. }}$.

Fig. 3 shows the relationship between SCVI and CSAI ${ }_{\text {scB. }}$. As expected, the $\mathrm{CSAI}_{\mathrm{SCB}}$ significantly increased in proportion to SCVI, and the relationship could be expressed by the following equation:

$$
\mathrm{CSAI}_{\mathrm{SCB}}=2.88 \times 10^{-4} \mathrm{SCVI} \quad\left(R^{2}=0.751, P<0.001\right) .(10)
$$

For Japanese cedar (Cryptomeria japonica D. DoN) and hinoki cypress, KAJIHARA $(1980 ; 1981)$ has showed that crown mantle volume was a good indicator of foliage mass. The SCVI in this study is the sunny crown mantle produced in a current year, and foliage which constitutes the SCVI was undoubtedly produced in the year. Thus, SCVI would be a good indicator of foliage mass produced in a current year. On the other hand,

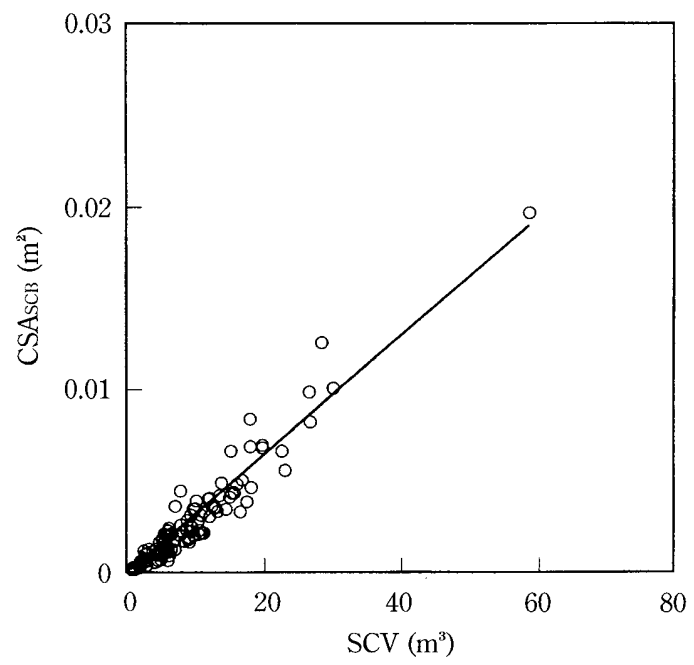

Fig. 2 Relationship between sunny crown volume (SCV) and stem cross-sectional area at sunny crown base $\left(\mathrm{CSA}_{\mathrm{sc}}\right)$ The solid line indicates the regression equation (9). according to pipe-model theory (SHINOZAKI et al., 1964), the foliage mass is in proportion to the cross-sectional area of the stem sustaining the foliage (YODA, 1971), implying that the increment of the foliage mass is in proportion to that of the cross-sectional area. The result in this study, which indicates the proportional relationship between SCVI and $\mathrm{CSAI}_{\mathrm{SCB}}$ as shown in Fig. 3, might be supported by these previous studies.

Fig. 4 demonstrates examples of the vertical distribution of CSAI for sampled trees. The vertical distributions obtained by eq. (8) with $\mathrm{CSAI}_{\mathrm{scB}}$ estimated using eq. (7) with parameters shown in eq. (10) fit well to CSAI observations. Fig. 5 shows the comparison of RMSEs in eq. (8) with estimated and observed $\mathrm{CSAI}_{\mathrm{SCB}} \mathrm{S}$. Although the RMSE in eq. (8) with estimated CSAI $\mathrm{SCB}_{\text {SB }}$ was larger than that in eq. (8) with observed $\mathrm{CSAI}_{\mathrm{SCB}}$ for each sampled tree, the vertical distribution obtained by eq. (8) with estimated $\mathrm{CSAI}_{\mathrm{SCB}}$ closely matched that of eq. (8) with observed $\mathrm{CSAI}_{\mathrm{SCB}}$ (Fig. 4). Furthermore, for overall fit, although eq. (8) with estimated $\mathrm{CSAI}_{\mathrm{SCB}}$ returned a larger RMSE value than eq. (8) with observed $\mathrm{CSAI}_{\mathrm{SCB}}$ did $\left(\mathrm{RMSE}=1.58 \mathrm{~cm}^{2}\right.$ for eq. (8) with estimated $\mathrm{CSAI}_{\mathrm{SCB}}$ and $1.15 \mathrm{~cm}^{2}$ for eq. (8) with observed $\mathrm{CSAI}_{\mathrm{SCB}}$ ), the difference in RMSE was only $0.43 \mathrm{~cm}^{2}$. This overestimation of the area of a circle results in slight overestimations of diameter as well; $0.055 \mathrm{~cm}$ for a $5-\mathrm{cm}$ diameter circle, $0.028 \mathrm{~cm}$ for a $10-\mathrm{cm}$ circle, and $0.014 \mathrm{~cm}$ for a 20 -cm circle. For measuring stem diameter, a diameter tape is the most consistent instrument. However, even if the tape is level and pulled taut, the measurement error is at most $0.05 \mathrm{~cm}$ because the tape is usually graduated in $0.1 \mathrm{~cm}$. In view of this fact, the difference in RMSE would be sufficiently small for predicting stem form.

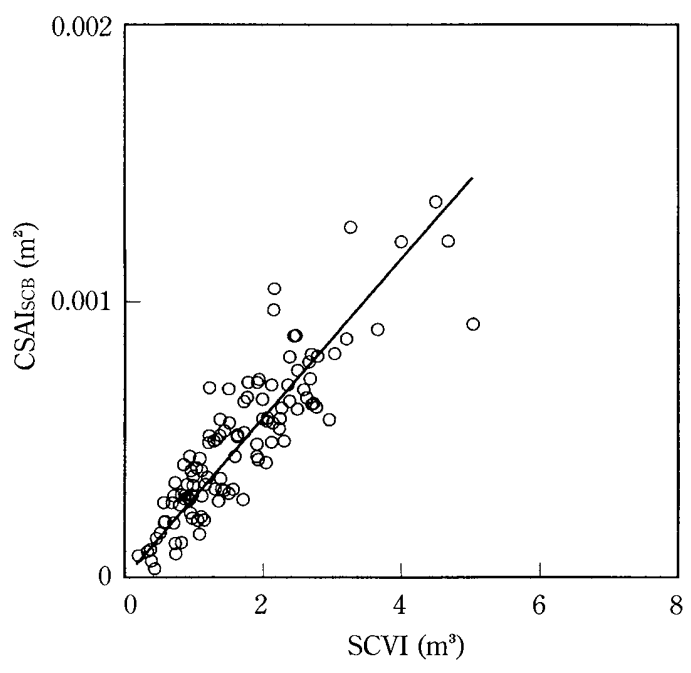

Fig. 3 Relationship between sunny crown volume increment (SCVI) and stem cross-sectional area increment at sunny crown base ( $\mathrm{CSAI}_{\mathrm{scB}}$ )

The solid line indicates the regression equation (10). 

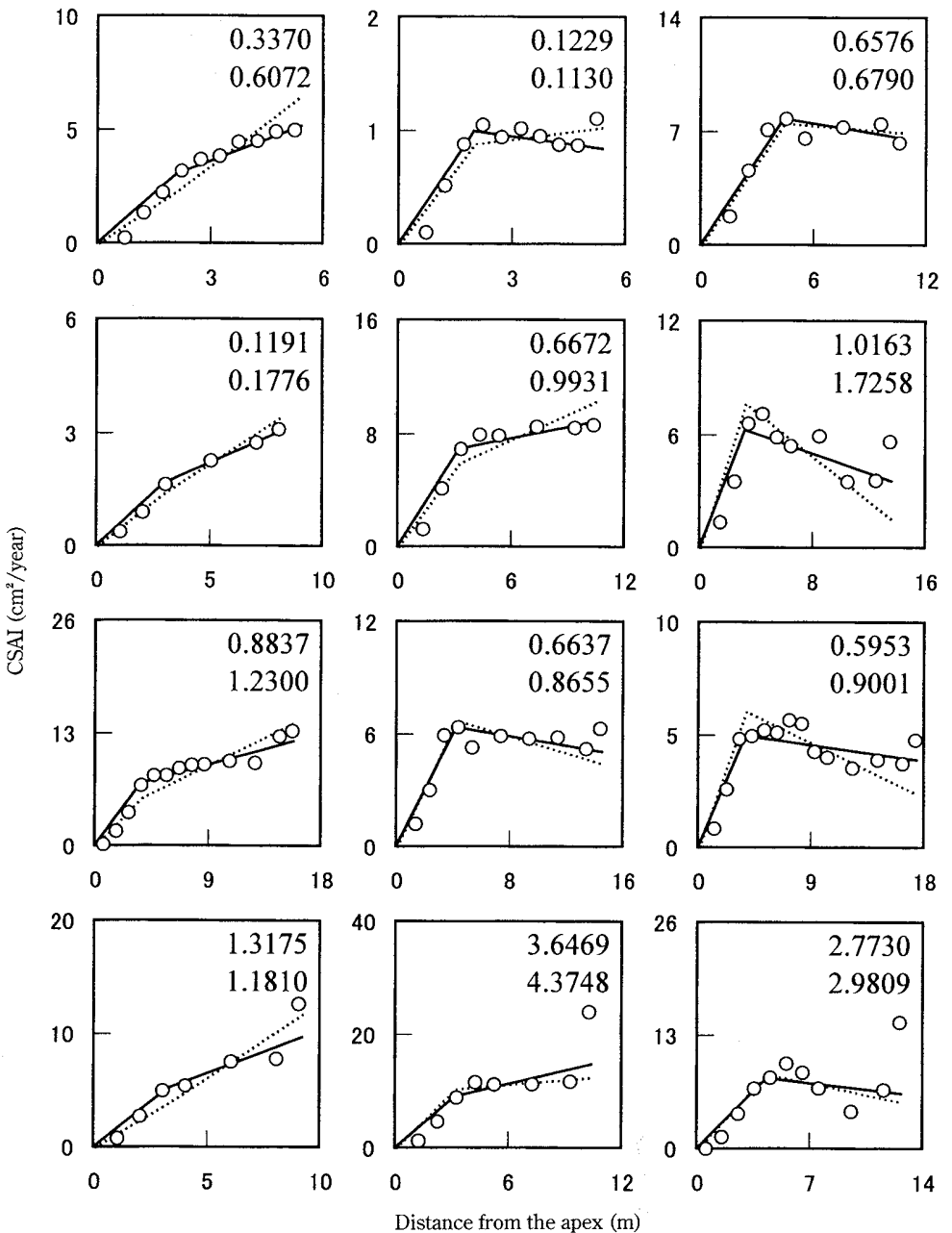

Fig. 4 Examples of the vertical distribution of stem cross-sectional area increments (CSAI) Open circles represent observations. Solid and dotted lines are fitted to eq. (8) with observed and estimated $\mathrm{CSAI}_{\mathrm{scB}}$. Upper and lower values in each graph represent root mean squared errors $\left(\mathrm{cm}^{2}\right)$ for eq. (8) with observed and estimated $\mathrm{CSAI}_{\mathrm{scB}} \mathrm{S}$, respectively.

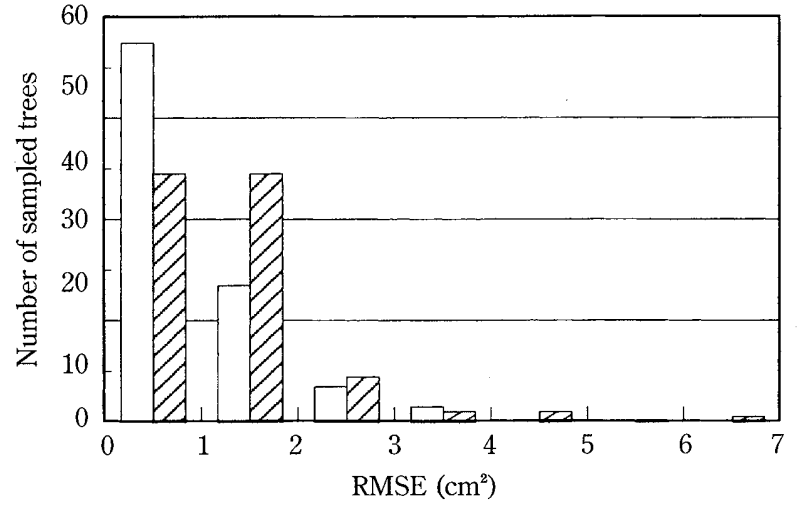

Fig. 5 Distribution of the root mean squared error (RMSE) for each sampled tree

Open and striped bars represent numbers of sampled trees for eq. (8) with observed and estimated $\mathrm{CSAI}_{\mathrm{scB}} \mathrm{S}$, respectively. 
SCVI can be estimated by using a model provides time streams of both sunny crown profile and SCL. WAGUCHI and UEDA (2005) have found that sunny crown profile for hinoki cypress could be described by the following equation:

$$
r=d_{1} \mathrm{HI}^{d_{2}} z^{d_{3}}
$$

where $d_{1}, d_{2}$, and $d_{3}$ are constants. Furthermore, WAGUCHI and UEDA (2006b) have developed a model for estimating SCL from stand density and HI for even-aged hinoki cypress stands. These results indicate that SCVI for hinoki cypress can be estimated from time streams of both stand density and HI. Thus, when $\mathrm{CSAI}_{\mathrm{SCB}}$ can be estimated using SCVI, combining these results reported by WAGUCHI and UEDA (2005; 2006b) with a total height growth model allows us to estimate $\mathrm{CSAI}_{\mathrm{SCB}}$ because stand density is generally a known variable. In conclusion, the assumption of the proportional relationship between SCVI and $\mathrm{CSAI}_{\text {ScB }}$ provides a useful approach for predicting vertical distribution of CSAI for hinoki cypress.

\section{LITERATURE CITED}

INOSE, M., (1982): A tree growth model based on crown competition in Todomatsu (Abies sachalinensis). 1. The relationship between crown development and volume increment. Bull. For. For. Prod. Res. Inst. 318: 103-127 (in Japanese with English summary)

KaJIHARA, M., (1980): Crown structure of sugi (Cryptomeria japonica) and the relationship between crown dimensions and leaf fresh weight. Bull. Kyoto Pref. Univ. For. 24: 49-63 (in Japanese with English summary)

KAJIHARA, M., (1981): Crown form, crown structure and the relationship between crown dimensions and leaf fresh weight of hinoki (Chamaecyparis obtusa). Bull. Kyoto Pref. Univ. For. 25: 1128 (in Japanese with English summary)

KaniHARA, M., (1982): Relationship between crown dimensions and stem volume increment in sugi (Cryptomeria japonica) and hinoki (Chamaecyparis obtusa). Bull. Kyoto Pref. Univ. For. 26: 16-23 (in Japanese with English summary)

Maguire, D.A. and HanN, D.W., (1989): The relationship between gross crown dimensions and sapwood area at crown base in Douglas-fir. Can. J. For. Res. 19: 557-565

Saigusa, Y., Kunisaki, T., Mizoue, N., Teraoka, Y. and Imada, M., (1996): Construction of forest information system: Modeling the stand growth of sugi and hinoki plantations based on the crown dynamics. Trans. Jpn. For. Soc. 107: 99-100 (in Japanese)

Shinozaki, K., Yoda, K., Hozumi, K. and KIRA, T., (1964): A quantitative analysis of plant form: the pipe model theory. 2 . Further evidence of the theory and its application in forest ecology. Jpn. J. Ecol. 14: 133-139

Waguchi, Y. and UEDA, M., (2005): A sunny crown profile equation for hinoki cypress based on the height increment. J. For. Plann. 11: $47-51$

Waguchi, Y. and UEDA, M., (2006a): A model for predicting the vertical distribution of cross-sectional area increments in hinoki cypress stems. J. For. Plann. 12: 31-35

WAGUCHI, Y. and UEDA, M., (2006b): Estimating sunny crown length using stand density, total height, and height increment in evenaged closed hinoki cypress stands. J. For. Plann. 12: 65-69

YoDA, K., (1971): Ecology of forests. Tsukiji Shokan, Tokyo, 331pp (in Japanese)
(Received 15 January 2007)

(Accepted 7 July 2008) 